\title{
The Role of Knowledge in Disaster Risk Reduction
}

\author{
Juergen Weichselgartner ${ }^{1,2} \cdot$ Patrick Pigeon $^{3}$
}

Published online: 16 June 2015

(c) The Author(s) 2015. This article is published with open access at Springerlink.com

\begin{abstract}
Disaster risk reduction policy and practice require knowledge for informed decision making and coordinated action. Although the knowledge production and implementation processes are critical for disaster risk reduction, these issues are seldom systematically addressed in-depth in disaster studies and policy programs. While efforts and improvements have been made with regard to data and information, only limited resources are committed to improving knowledge management structures and integrating knowledge systems at different spatial levels. The recently adopted Sendai Framework for Disaster Risk Reduction 2015-2030 addresses knowledge-related issues and provides the opportunity to highlight the critical role of knowledge in disaster risk reduction. This article presents insights into potential conceptualizations of knowledge that would advance disaster research and policy. We use cases from France to illustrate challenges of and pathways to disaster risk reduction. We suggest to further strengthen efforts that improve our understanding of the connections between disaster risk, knowledge, and learning. A better integration of multiple scales, different societal actors, various knowledge sources, and diverse disciplines into disaster risk research will increase its relevance for decision-makers in policy and practice. Well-targeted incentives and political backing will improve the coherence,
\end{abstract}

Juergen Weichselgartner

juergen.weichselgartner@gmail.com

1 Department of Architecture and Urban Studies, Politecnico di Milano, 20133 Milan, Italy

2 Department of Geography, Ludwig-Maximilians University Munich, 80333 Munich, Germany

3 Department of Geography, Savoie-Mont-Blanc University, 73376 Le Bourget-du-Lac, France coordination, and sharing of knowledge among various actors and arenas.

Keywords Disaster risk reduction - France . Information management · Knowledge systems . Natural hazards · Risk prevention

\section{Introduction: Where Is the Knowledge We Have Lost in Information?}

The observation that losses caused by natural hazards have been continuously increasing despite the concurrently growing volume of research on natural risks prompted White et al. (2001), almost 15 years ago, to highlight the gap between what is known about natural hazards and disaster mitigation, on the one hand, and how research findings are translated into disaster risk reduction (DRR) policies and programs, on the other hand. For the first time, hazard researchers explicitly mentioned that improved knowledge was not by itself sufficient to reverse the upward trend in disaster statistics and called into question how knowledge is used in hazard management. In their statement "knowing better and losing even more", they raised important questions about the trend towards higher disaster losses: Is nature getting more hazardous or is society becoming more vulnerable? Is understanding of the causes of the losses inadequate despite increasing research efforts? Or is existing knowledge not applied or not used effectively? In a complementing analysis of the contradictory development of "knowing more and losing more", Weichselgartner and Obersteiner (2002) claimed that despite an immense expansion of risk-related knowledge systems-special research programs and institutes, specialized journals, advanced technology, increased financial 
resources, and so on-insufficient progress has been made in converting research findings into concrete applications in practical DRR management. This has raised questions about potential barriers in the science-policy-practice interface that hinder the effective use of existing knowledge.

White et al. (2001) examined four possible explanations for the situation in which more is lost while more is known: (1) knowledge continues to be flawed by areas of ignorance; (2) knowledge is available but not used effectively; (3) knowledge is used effectively but takes a long time to take effect; and (4) knowledge is used effectively in some respects but is overwhelmed by increases in vulnerability and in population, wealth, and poverty. On the basis of their review, the authors offered two concluding observations. The first is that better appraisal is needed of the actual results of applying the best available knowledge in the best possible way at community and other levels. The second is that there is a need to build upon past achievements in creating more understanding of natural hazards, by better integrating that knowledge into the wider efforts directed at sustainable development. Similar observations have been made by other scholars, for example, Vogel et al. (2007), Gaillard and Mercer (2013), and Weichselgartner and Kasperson (2010). The latter analyzed scientific assessments in the DRR domain and identified a number of functional, structural, and social factors inhibiting joint knowledge production of producers and users. Researchers often do not consider the needs of potential users in policy and practice when conducting research and do not systematically produce directly usable risk information and, likewise, decision-makers do not always use the most appropriate available scientific information to make policy decisions.

In spite of the importance of the critical connection between DRR and knowledge, the questions raised more than a decade ago are still not fully answered today. The former director of the secretariat of the United Nations International Strategy for Disaster Reduction (UNISDR) pointed out that during the last 25 years the evolution in knowledge and application of DRR has been uneven (Briceño 2015). We believe that the domains of disaster risk reduction, knowledge management, and social learning are interlinked and that understanding these connections can help us to improve DRR. This view is supported by both scholarly research (Glantz and Baudoin 2014; Renn 2015) and international organizations (UNISDR 2015a; Briceño 2015). Moreover, the Sendai Framework for Disaster Risk Reduction 2015-2030 (SFDRR)—adopted by representatives from 187 United Nations member states on 18 March 2015 at the Third UN World Conference on Disaster Risk Reduction (WCDRR-3) in Sendai, Japanaffirms in paragraph 14 of the preamble that "in order to reduce disaster risk, there is a need to address existing challenges and prepare for future ones by focusing on: monitoring, assessing and understanding disaster risk and sharing such information and how it is created; strengthening disaster risk governance and coordination across relevant institutions and sectors and the full and meaningful participation of relevant stakeholders at appropriate levels" (UNISDR 2015b).

This article addresses some of the challenges related to knowledge production and implementation in the DRR domain. The motivation is twofold: we believe that the role of knowledge requires attention in DRR research, policy, and practice. Thus, we encourage hazard, vulnerability, risk, and disaster scholars to integrate issues of knowledge into their research. We are convinced that addressing such issues will lead to significant improvements in DRR policy and practice. We promote a "lessons learned about lessons learned" process and encourage DRR scholarship to open up their knowledge production processes by integrating different kinds and modes of knowledge. In Sect. 2, we outline our understanding of knowledge and relate it to the new SFDRR. In Sect. 3, we use the example of the disaster linked to storm Xynthia on the west coast of France to illustrate common cases of ignorance and institutional disintegration, pointing at limitations of current DRR policies. In Sect. 4, we focus on the fragmentation of knowledge the French National Observatory for Natural Risks (Observatoire National des Risques Naturels, ONRN) is trying to overcome, as an example of implementing the recommendations of the SFDRR. Section 5 concludes with some thoughts on key challenges that should be addressed jointly by DRR science and policy.

\section{Disaster Risk Reduction and Knowledge}

Before outlining some challenges in DRR-related knowledge production and application, we need to explain our conceptual approach to knowledge. As visualized in Fig. 1, we distinguish between different qualitative levels of understanding: facts, data, information, knowledge, and wisdom. Although we adopted our organization of understanding from widely recognized models in the information and knowledge literatures (Cleveland 1982; Ackoff 1989; Rowley 2007), our intention is neither to promote a specific approach nor to contribute to the debate on the theoretical underpinnings of information science. However, we believe that a qualitative distinction of the different levels of understanding provides a sound basis from which researchers can better relate to policymakers and practitioners in the DRR domain. Moreover, a more differentiated use of the term "knowledge" is needed because in the floods of information of the information age the term is 


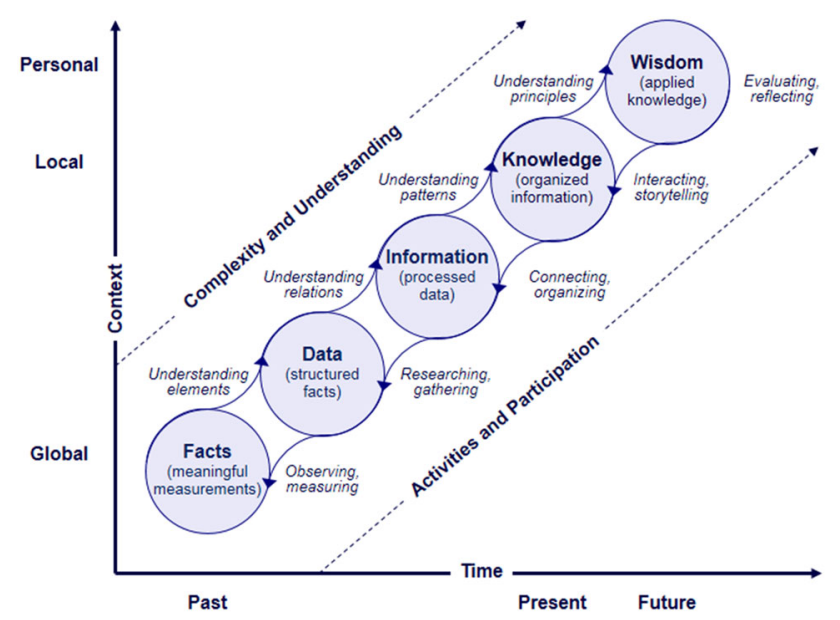

Fig. 1 The continuum of understanding

often confused and replaced with "providing information". This is partly related to the advancement of information technology, which is increasingly producing and delivering facts and data, although much of that information remains unorganized, untapped, or unused.

\subsection{From Facts to Wisdom}

All of the elements of the continuum of understanding are abstract concepts and the distinctions between each stage are fuzzy. For instance, what constitutes information for one person may be just data to others because they may not have the context needed to make full use of that information. We agree with Cleveland (1982) that it is not important to search for universal agreement on the distinctions between the terms. For the purpose of this article, it is sufficient to consider data as a set of objective but meaningless facts that have not been processed and contextualized into usable information. In a scientific context, facts and data are generated through research and represented as structured records of measurements and observations. While facts and data do not have any inherent structure, information has context. As indicated by the original meaning of the verb inform, that is, "to give form to" something, to become information data need to be intentionally processed, organized, and structured in a useful way so that we can draw conclusions. Information is "data with meaning" that makes a difference.

Knowledge is created by accumulating and organizing information with respect to breadth, depth, and amount. Facts, data, and information are necessary mediums for eliciting and constructing knowledge. According to Davenport and Prusak (1998, p. 5) knowledge is "a fluid mix of framed experience, contextual information, values and expert insight that provides a framework for evaluating and incorporating new experiences and information".
While information is static, knowledge is dynamic, built through social interaction and experience, with the result that the "objective" facts, data, and information are considered and evaluated from different perspectives. One can neither count on one person's knowledge transferring to another, nor assume that a knowledge transfer will have the desired impact. This is why awareness raising, training, and education are reasonable components of DRR policies, and why integrated, coproduced knowledge is so critical to implement. In the "linear" knowledge production model, academia's best contribution to problem resolution lies in the adequate transfer of knowledge (through communication, education, patenting, or publication) to other actors charged with the implementation of such knowledge in the form of products, procedures, regulations, or problem solutions. A nonlinear understanding of knowledge production, however, assumes that relevant knowledge can be produced by any kind of actor-academic or lay-who must be acknowledged for his or her specific perspective on a given problem (Weichselgartner and Truffer 2015). Different actors can be the origin of new ideas, and knowledge flows can go in all directions, from practitioners to researchers, or from basic science to policy, and so on. In the DRR domain, however, the coproduction of knowledge is limited and implementation gaps between research and practice persist. A recent analysis of the characteristics of disaster risk research illustrates that most research on disaster risk is still discipline- or multidiscipline-centric, largely produced by North American and European scholars, and has limited success as an evidentiary basis for policy improvements (Gall et al. 2015).

Wisdom represents an even higher level of understanding: it is evaluated and reflected understanding, or integrated and applied knowledge. As with knowledge, wisdom operates within people. Experience that creates the building blocks for wisdom can be shared, but needs to be communicated with even more understanding of the personal contexts than in the case of knowledge sharing. Through the transitions from facts to wisdom, not only understanding increases but also the degree of participation and connectedness, resulting in a higher complexity. As Cleveland (1982) summarizes it: information is horizontal, knowledge is hierarchical, and wisdom is flexible. Furthermore, facts, data, and information deal with the past, whereas knowledge deals with the present. When we gain wisdom, we add more context and start dealing with the future as we are now able to envision the path ahead and design for what will be, rather than for what is or was. While the elements shown in Fig. 1 are abstract concepts and clear distinctions are difficult, a differentiation of the qualitative levels of understanding appears useful for identifying shortcomings in current DRR. Systematic research on DRR-related knowledge systems would not 
only advance our schematic understanding but also provide important insights into the roles of knowledge in DRR.

A point that is significant for DRR efforts and that is addressed in the new SFDRR is the circumstance that knowledge is embedded in a physical object (person or organization) and shaped by perception, experience, and culture. The same applies to knowledge products such as knowledge management databases, information platforms, or lessons learned documents. Therefore, one needs to distinguish between two types of knowledge: explicit and tacit (Polanyi 1967; Nonaka and Takeuchi 1995). Explicit knowledge can be easily processed by a computer, transmitted to others in formal language and electronically, or stored in databases. It is this type of knowledge that current knowledge management practices try to capture and most of the knowledge issues addressed in the SFDRR deal with explicit knowledge. In contrast, tacit knowledge is personal knowledge embedded in individual experience and involves intangible factors, such as personal beliefs, insights, perspectives, and value systems. It is knowledge that is hard to encode, formalize, and articulate with formal language. It is ephemeral, transitory, personal, contextspecific, and cannot be resolved into information or itemized in the manner characteristic of information. Before it can be communicated, it must be converted into a formwords, models, or numbers-that can be understood. Moreover, tacit knowledge has two dimensions: a technical (procedural) one, encompassing the kind of informal experiences and skills often captured in the term knowhow, and a cognitive one, encompassing beliefs, perceptions, ideals, values, emotions, and mental models. As we will illustrate in the next sections, it is particularly these dimensions of tacit knowledge that need to be better addressed and captured by DRR research and policy.

\subsection{The Sendai Framework for Disaster Risk Reduction (SFDRR) and Knowledge}

The SFDDR takes into account that informed decision making and coordinated action require reliable knowledge. The Sendai Framework's implementation is guided by several principles, and Paragraph 19 directly refers to knowledge: "Disaster risk reduction requires a multi-hazard approach and inclusive risk-informed decision-making based on the open exchange and dissemination of disaggregated data, including by sex, age and disability, as well as on the easily accessible, up-to-date, comprehensible, science-based, non-sensitive risk information, complemented by traditional knowledge" (UNISDR 2015b, p. 9). While this statement seems straightforward at first glance, the problem of who should collect, disaggregate, and disseminate the data is less so. Additionally, there are some details on the "how" that require further explanation and discussion, a process that Glantz (2015) accurately referred to as "lessons learned about lessons learned".

The SFDRR sets four priorities for action: (1) understanding disaster risk; (2) strengthening disaster risk governance to manage disaster risk; (3) investing in disaster risk reduction for resilience; and (4) enhancing disaster preparedness for effective response, and to "Build Back Better" in recovery, rehabilitation, and reconstruction. Particularly Priority 1 relates to issues of knowledge, listing 23 requirements that are directly or indirectly linked to information and knowledge (UNISDR 2015b). For instance, point (h) advises to "promote and improve dialogue and cooperation among scientific and technological communities, other relevant stakeholders and policymakers in order to facilitate a science-policy interface for effective decision-making in disaster risk management" (UNISDR 2015b, p. 11). An effective implementation of this advice, however, requires a certain understanding of knowledge production processes, of the existence of different types of knowledge, and of the causes hindering the transfer and use of information. Therefore, it would be useful to present potential means and provide actual opportunities for bridging gaps between bottom-up and top-down actions, between local and scientific knowledge, and between issue domains such as DRR and climate change adaptation. Research in this direction exists and propositions have been made (Kasperson and Berberian 2011; Gaillard and Mercer 2013; Kelman et al. 2015).

The SFDRR (UNISDR 2015b, p. 9) points to the importance of promoting "the collection, analysis, management, and use of relevant data and practical information" at national and local levels, as well as to "ensure its dissemination, taking into account the needs of different categories of users". This is reasonable since many countries do not systematically collect disaster-related facts, data, and information. Depending on the agency or institution, the collection ranges from hazard type to risk exposure and disaster damage. Thus, knowledge is scattered among various actors and arenas with limited coherence, coordination, and sharing. The existence of a national web site that displays disaster-related data is not evidence for the existence of a national disaster information system. Little information is available on the extent to which households, businesses, and government institutions from outside the sector visit these web sites or whether the information available is actionable (UNISDR 2015a).

More importantly, there is hardly any reassessment and evaluation of collected and used data and information. Learning includes the processes of generating, acquiring, and sharing knowledge, as well as incorporating the newly acquired knowledge into future activities. Especially after disaster occurrence, it would be appropriate to reconsider 
existing data, information, and knowledge, preferably within larger spatial and temporal scales to capture feedback loops (López-Peláez and Pigeon 2011).

While closer cooperation between academics and practitioners in making data available for research purposes is desirable, the common practice is that datasets are not shared but guarded by secrecy and nondisclosure agreements (Milton 2014). Even when datasets are freely accessible, they often remain empirical, unstructured, and meaningless facts. As a result, although risk information is being generated and disseminated on a large scale, we do not know how far it reaches and whether it changes risk perceptions and awareness levels (UNISDR 2015a). In the DRR domain, a drawback is the lack of agreed standards and clearly defined responsibilities and accountabilities in knowledge management.

According to Senge (1990, p. 19), learning organizations are "organizations in which people continually expand their capacity to create the results they truly desire, where new and expansive patterns of thinking are nurtured, where collective aspiration is set free, and where people are continually learning to see the whole together". The basic rationale for such organizations is that in situations of rapid change only those organizations that are flexible, adaptive, and productive will excel. For this to happen, Senge argues, organizations need to discover how to tap people's commitment and capacity to learn at all levels. Such a view is in contrast to many of the recommendations outlined in the SFDRR. Top-down activities that lack incentives and possibilities for integrating diverse societal actors will inevitably disregard valuable experience and expertise.

The 2002 Elbe River floods in Germany and Hurricane Katrina in 2005 in the United States are prominent examples illustrating that for DRR-related organizations effective policy implementation is as important as making the right policy. The river floods and the hurricane not only exposed the vulnerability of highly developed countries to natural hazards but also disclosed deficiencies in social learning and applying knowledge. In both countries, the investigation of DRR and response processes characterized the responses to the two events as "a failure of initiative" rather than "a failure of knowledge" (Weichselgartner and Brévière 2011). But there is, of course, a nexus between the two. Both knowledge and initiative require information and a coordinated process for sharing it. The disasters highlighted shortcomings in effectively transferring organized information into applied knowledge, that is, knowledge into wisdom. Katrina was known to be headed to New Orleans several days before the hurricane made landfall, and the potential damage had been known and understood years ahead of time (Select Bipartisan Committee to Investigate the Preparation for and Response to Hurricane Katrina 2006). Yet the socioeconomic and political impacts of the hurricane were enormous. In April 2006, the Elbe River again caused severe damage-despite a comprehensive lessons-learned process initiated shortly after the Elbe River floods in 2002 (DKKV 2004). The failure to mitigate and respond more effectively to natural hazardswhich in both cases had been predicted in theory for many years, and forecast with startling accuracy for days ahead of time- underlines the importance of addressing the distinct domains of disaster risk reduction, knowledge management, and social learning together.

While the SFDRR addresses both the creation and dissemination of knowledge through various recommended activities, the analysis of available and used knowledge is hardly mentioned. However, an evaluated and reflected understanding based on a lessons-identified approach is critical to further improving DRR towards applied knowledge. Organizations in the DRR domain must increase their efforts to identify lessons learned and move from singleloop to double- and triple-loop learning (Argyris and Schön 1978). Single-loop learning refers to an incremental improvement of action strategies without questioning the underlying assumptions. Given or chosen goals, plans, strategies, and rules are operationalized rather than questioned. Double-loop learning refers to a revisiting of assumptions-cause-effect relationships are a good example from the DRR domain-and to questioning the governing variables themselves by means of a critical reexamination. In triple-loop learning, one begins to reconsider underlying values, beliefs, and worldviews. Such learning may then lead to an alteration in the governing variables and a structural change or a shift in the way in which strategies are framed. Researchers have developed frameworks that can guide analysis of how multilevel and multiloop learning processes influence the dynamics of factors underlying the adaptive capacity of governance and management systems, for instance regarding natural resources and floods (Pahl-Wostl 2009; Pahl-Wostl et al. 2013).

The SFDRR points at important shortcomings in the DRR domain, above all how little integration of knowledge systems occurs at community, regional, and national levels. The same is true of the institutional level. Closer collaboration between the different organizations working in DRR would improve the quality and utilization of their "knowledge products". Closer cooperative efforts with organizations from related knowledge domains such as climate change would harness additional expertise (Kelman 2015). More incentives and political backing for knowledge sharing are needed. Hardly any resources are committed to specific efforts to improve knowledge management in DRR. Collected data and information are usually not organized for different audiences and translated into different languages. Issues of power and competition 
at institutional and administrative levels can severely hinder the sharing of data and information. In the following sections, we portray the impacts of storm Xynthia on the Atlantic coast of France to illustrate some of the challenges the implementation of the SFDRR faces, as well as the practical efforts of the French National Observatory for National Risks that are aimed at reducing some of the existing shortcomings.

\section{The Challenge of Ignorance: Storm Xynthia in France}

In February 2010, storm Xynthia hit the French Atlantic coast, causing over forty fatalities and direct losses of more than $€ 2.5$ billion (Cour des comptes 2012). In particular, the cities of La Faute-sur-Mer, L'Aiguillon-sur-Mer, and La Tranche-sur-Mer (Vendée département) suffered severe damage. A number of circumstances contributed to the fatal impacts of the storm, including: limited ministerial (préfectorales) actions to enforce the production or implementation of local development plans, resistance of communities to adopt risk prevention plans, inadequate spatial planning, lack of maintenance and failure of risk defense measures, and inappropriate risk considerations by the real estate market (Pigeon 2012a, 2013). Moreover, a critically important part of disaster management failed: the storm surge warning was not understood by the local authorities and the public.

Météo-France had provided a warning for the storm on all the TV networks and given storm surge warnings. However, the weather maps of Météo-France that were shown on TV provided no information on the risk for flooding. Civil servants did not understand the nature of the flood risk, illustrated by interviews with key decisionmakers. The mayor of La Faute-sur-Mer said he did not know the storm posed a flood risk to his city and a highranking official (sous-préfet de la Vendée) spoke of the impossibility of evacuating 400,000 people on account of the storm, when evacuating a few thousand people would have saved the 29 lives lost in La Faute-sur-Mer (Kolen et al. 2010). All the fatalities were living in houses built after 1980 and more than two-thirds were over 60 years old, a clear sign that limited analysis had been done to understand the trends and impacts of spatial and demographic development and their spatiotemporal significance for disaster risks.

Storm Xynthia disclosed the desire of local authorities for site development, ignoring natural risks in spite of the information available on flood-prone areas. Figure 2 illustrates the coastal area of La Faute-sur-Mer and the continuous cultivation of the flood risk zone between the Lay River and the Atlantic Ocean. The building
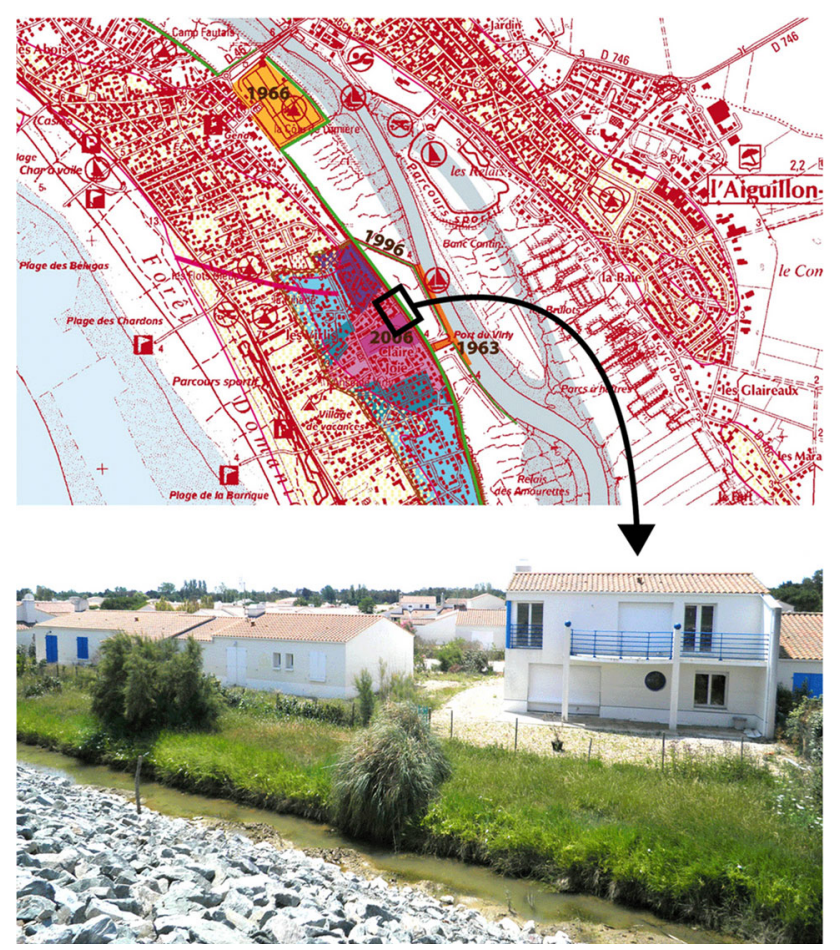

Fig. 2 Houses, such as these in La Faute-sur-Mer, were built deliberately in flood-prone areas (Source Pigeon 2012a)

development dates back to the 1960s (blue color), however, especially infrastructure build after 2006 (red color) was flooded (Pigeon 2012a). Moreover, the storm revealed the weakness of the State's representative (that is, the so-called préfet, representing the State in the département, a local subdivision of French national territory; see Pigeon 2013 for more details) to enforce existing laws in the face of this desire (Cour des comptes 2012). As a result of the disaster, the central government in Paris adopted a "plan submersions rapides" (a response plan for flood risks) and decided to remove houses in some of the affected areas. The plan turned out to be controversial and local opposition from inhabitants and elected officials grew, mainly because the affected people felt excluded from the decision-making process. Not only deficits in operational DRR and emergency management, but (on-going) conflicts between citizens, national government, and local authorities on regulations and measures underline the important role of knowledge in reducing disaster risk.

The case study illustrates that the sharing of data and information is often prevented by underlying issues of power and competition at institutional and administrative levels, preventing the necessary "third loop" of learning (Zia and Wagner 2015). It demonstrates how existing information and knowledge on flood risk and flood prevention is scattered among various actors and arenas with limited coherence, coordination, and sharing. Despite the 
fact that DRR information was available and had been collectively discussed during sessions held by the municipal council of La Faute-sur-Mer (Pigeon 2012a), 29 citizens lost their lives in their homes. The provision of information alone is not an effective means to prevent disasters. It is essential to consider the production and application of knowledge and its integration with the values and interests of various stakeholders and institutions at different scales into the risk policy-making process (Renn 2015). This is strongly linked with issues of trust in and acceptance of decisions collectively taken.

\section{The Challenge of Fragmentation: From Tazieff's Law to the French National Observatory for Natural Risks}

The case of La Faute-sur-Mer, and similar cases that can be found around the globe, underline the need to better integrate information and knowledge as suggested in the SFDRR (UNISDR 2015b). While the degree of integration was still poor in France in 2010, the country "learned its lesson" and in 2012 established the French National Observatory for Natural Risks (Observatoire National des Risques Naturels, ONRN) as a multistakeholder information platform. However, cultural context and national policies influence the production, transfer, and implementation of DRR-related knowledge and such peculiarities have to be taken into account when implementing the SFDRR (Spiekermann et al. 2015).

In 1982 the so-called Tazieff's law (named after the politician who promoted it) was introduced in France, a law that reconsidered the existing DRR policies. In accordance with this law, the French government issues ministerial orders declaring that a natural disaster has occurred (arrêtés interministériels de déclaration de catastrophe naturelle), in the case of losses related to events such as floods, landslides, or other natural hazards. These ministerial orders are administrative and political decisions, allowing insurance companies to pay for damages insured citizens experience. Since Tazieff's law, every citizen has to pay an extra-premium to insure against "natural disasters" when insuring a car or house against theft or fire. Since 1982, insurance companies and the French State have been working hand-inhand with respect to disaster risk reduction.

This situation offers the possibility of sharing information coming from various major stakeholders at the national scale. The French State provides information on official disaster declarations and on tools towards disaster prevention in the form of risk prevention plans (RPP). Insurance companies provide information on insured damages. Integrating different kinds of DRR information is made possible and relevant by the institutional association between major stakeholders, in spite of the limitations of existing and available information. In this case, damage refers to insured goods only. Today, there are more insurance companies willing to share their collected data with scientists, which has resulted in several Ph.D. dissertations on DRR-related aspects (see for example, Gérin 2011; André 2013; Bourguignon 2014). An examination of the accuracy of the information insurance companies deliver at local scales revealed discrepancies and limitations coming from various sources: methodological biases are numerous (André 2013). These Ph.D. dissertations discussed how the information available has to be considered as a rough basis for a first assessment of the intensities of the damage effectively experienced. The information provided by insurance companies does not, of course, take into account goods that are not insured, that is, overall total losses are higher. In spite of information shortcomings, France meets some of the major requirements outlined in the SFDRR, especially with respect to promoting the collection, analysis, management, and use of relevant data and practical information.

After the storm Xynthia and Var area floods (February and June 2010, respectively), a public-private partnership arrangement was proposed, towards having a platform for risk data collection and sharing among stakeholders and regions. In May 2012, this led three main stakeholders to create a dedicated platform, named Observatoire National des Risques Naturels (ONRN): the French State represented by its ministry of Ecology in charge of DRR policies, Caisse Centrale de Réassurance (CCR), and Mission Risques Naturels (MRN). The latter represents the two French insurance trade associations, Fédération Française des Sociétés d'Assurances (FFSA) and Groupement des Entreprises Mutuelles d'Assurances (GEMA).

According to its official site (http://www.onrn.fr), the ONRN will "provide a place where various stakeholders can find information on natural risks and indicators towards reducing vulnerability". This aim is consistent with the international trend to promote knowledge management systems for DRR, allowing that relevant information is available and accessible at all levels, to all stakeholders, through networks, development of information sharing systems (UNISDR 2014). The data, information, and knowledge sharing process benefits ONRN user groups who focus on risk management issues for a specific territory or theme. Various stakeholders support the ONRN, from NGOs to the private sector, including research and education, local authorities, government agencies, and the French Government. The ONRN portal web site gives access to data provided by more than 100 institutions, for instance regarding exposure, losses, and prevention policies, mostly at the municipal scale. Compared to the previous individual databases, the integration of diverse information provides a better qualitative level of understanding. 
Relying on both its institution networking and the information on specific indicators, the ONRN allows local as well as national stakeholders to access local-scale data and information, for example, with regard to flood risk and losses. Through the web-based platform, it becomes possible to cross-check information at any territorial grid location, such as the number of people living in flood-prone areas, cumulated insured losses from past floods, and on existing risk prevention efforts, for example, land-use planning regulations or risk reduction measures. The ONRN can serve as a stimulating example for other countries of how to implement a mechanism to "systematically evaluate, record, share and publicly account for disaster losses and understand the economic, social [...] impacts, as appropriate, in the context of eventspecific hazard-exposure and vulnerability information", as recommended by the SFDRR (UNISDR 2015b, p. 10).

The ONRN responds to the need for more preventionoriented policies and for reducing the fragmentation of information and knowledge. Its multistakeholder information platform allows the assessment of DRR policies, in line with the point the SFDRR makes about the need to achieve a better understanding of disaster risk and reach actionable plans. For instance, the current trend of decreasing hazard events in France that have been officially declared as disasters draws attention to the benefits and limitations of DRR policies (Nussbaum and Pigeon 2015). Such assessments need to reconsider profoundly how information and knowledge is being shared between institutions and stakeholders-an issue that is not addressed in the necessary detail in the SFDRR. Moreover, the question is still pending of how to use existing information and knowledge in order to increase the local recognition and sharing of existing DRR policies in spite of their limitations.

The limitations French DRR policy has faced and still does explain why the French State and insurance companies decided to establish the ONRN as a means of reducing information fragmentation between institutions and stakeholders. This decision aligns with one of the main recommendations of the SFDRR (UNISDR 2015b, p. 11): "Promote investments in innovation and technology development in long-term, multihazard and solution-driven research in disaster risk management to address gaps, obstacles, interdependencies and social, economic, educational and environmental challenges and disaster risks". This is an important step toward the transition of information into knowledge.

The La Faute-sur-Mer case underlines that existing prevention tools such as RPPs are not sufficient to prevent future disasters. The municipality had a RPP, which was approved by the Préfet in 2007, but strongly opposed by local stakeholders and the municipality itself. However, risk zonation and risk prevention planning can contribute to reduce future damages - if accepted and enforced (Pigeon 2012b).
The issue now is more about whether local stakeholders are better included in the decision-making process than about the existing tools or information about DRR. Therefore, power relationships are a critical issue (Renaud et al. 2013). This raises the question of how ONRN can function as a knowledge platform, not only for delivering assessments and creating new knowledge, but also for contributing more to DRR at the local scale during decision-making processes. In particular, at its present stage, the ONRN cannot address point (i) of the SFDRR under Priority 1 (UNISDR 2015b, p. 11): "Ensure the use of traditional, indigenous and local knowledge and practices, as appropriate, to complement scientific knowledge in disaster risk assessment and the development and implementation of policies".

The ONRN has the potential to support the integration of local information coming from diverse stakeholders. Provided by more than a hundred DRR-related institutions, the data and information serve as a basis for discussing the relevant issues of uncertainties and fragmentation. The ONRN provides explanations with respect to the methodologies behind indicators and makes explicit the limitations to strengthen confidence in DRR policies. Visualization methods and their associated models are among many approaches that can assist in stakeholder engagement and reducing the gaps between scientists gathering information, planners making decisions, and the communities affected by the decisions. In order to achieve such goals, it would also be necessary to allow local information coming from local stakeholders to be more integrated into the decisionmaking process, and into the knowledge platform itself. This "bottom-up" enrichment of the ONRN, mainly through involvement of local and regional observatories, applying the subsidiarity principle, is a priority for the years to come.

DRR tools such as the ONRN offer the possibility to display disaster risk-related information in a more consistent and precise manner and with a higher resolution than it was possible in the past. The platform allows the identification of localities with a high exposure to natural hazards, high frequencies of disasters, and/or high insured losses. Moreover, it is possible to identify disaster trends and, most importantly, municipalities without a RPP, making the ONRN an advanced open access database with regard to DRR (Groeve et al. 2014).

\section{Concluding Thoughts on Key Challenges}

Continuing disasters worldwide remind us that we need to further advance our scientific understanding and policy action on DRR — as well as better connect the two, keeping in mind White et al.'s (2001) observations which are still 
applicable today. They are also clear indicators that risk assessments, warning systems, legislation, and institutional and technical capacities that focus on physical hazard processes without addressing social vulnerability and resilience are incomplete and insufficient. While the essence of any DRR policy needs to be oriented towards reducing social vulnerability, "the larger academic community still dedicates greater resources to a highly specialized understanding of individual natural hazards, with a greater interest on the natural process than on their social impact" (Briceño 2015, p. 3). Such a dedication of resources is supported by a (science) policy that urges researchers to focus on extreme disaster events. There are at least two drawbacks when shifting the lenses from smaller and frequent to extreme and rare events: this approach takes away resources and distracts attention from addressing (1) the structural processes causing vulnerability; and (2) the social processes constructing the relationships between data, information, knowledge, and wisdom.

The SFDRR addresses important issues of DRR and pays more attention to the role of knowledge production and implementation than past international frameworks and strategies. In particular, it provides valuable recommendations regarding the creation and dissemination of knowledge. While this is a step in the right direction, the essential next step is to move towards "triple-loop" learning and transforming the current social production of risk information itself, with a shift in focus from the production of risk information per se towards coproduced risk knowledge that is understandable and actionable by different kinds of users. More guidance is needed to strengthen mechanisms and platforms for the analysis of existing as well as newly created knowledge. Likewise, a stronger engagement is necessary with regard to the essential transformation of knowledge into wisdom.

Knowledge production and transfer occurs through social interactions involving both explicit and tacit knowledge. As illustrated by the practical French example, national context and culture influence the development and implementation of knowledge management systems. Therefore, it is critical to further promote a change in the production mode of risk information at a national level: "from measuring risk as an objective externality that can be reduced towards understanding risk as both an opportunity and a threat, and towards improved identification and estimation of the causes and consequences of risk generation and accumulation" (UNISDR 2015a, p. xviii). This requires concerted action with regard to capacity and skill development in information and knowledge management. Ultimately, research and decision making in DRR is not only about "managing changes caused by disasters" but also about "creating systemic changes" so that people are less vulnerable to disasters.
Acknowledgments This article partly describes work in progress in the context of the FP7 project Enabling Knowledge for Disaster Risk Reduction in Integration to Climate Change Adaptation (KNOW-4DRR, http://www.know4drr.polimi.it). The whole is more than the sum of its parts.

Open Access This article is distributed under the terms of the Creative Commons Attribution 4.0 International License (http://creativecommons.org/licenses/by/4.0/), which permits unrestricted use, distribution, and reproduction in any medium, provided you give appropriate credit to the original author(s) and the source, provide a link to the Creative Commons license, and indicate if changes were made.

\section{References}

Ackoff, R.L. 1989. From data to wisdom. Journal of Applied Systems Analysis 16: 3-9.

André, C. 2013. Analysis of damage associated with coastal flooding and evaluation of costs incurred to homes from insurance data (Analyse des dommages liés aux submersions marines et évaluation des coûts induits aux habitations à partir des données d'assurance). Ph.D. dissertation, Université de Bretagne occidentale, Brest.

Argyris, C., and D. Schön. 1978. Organizational learning: A theory of action perspective. Reading: Addison Wesley.

Bourguignon, B. 2014. Events and territories: The costs of floods in France. Spatiotemporal analysis of insured damages (Evénements et territoires: le coût des inondations en France. Analyses spatio-temporelles des dommages assurés). Ph.D. dissertation, Université Paul Valéry-Montpellier III, Montpellier.

Briceño, S. 2015. Looking back and beyond Sendai: 25 years of international policy experience on disaster risk reduction. International Journal of Disaster Risk Science 6(1): 1-7.

Cleveland, H. 1982. Information as resource. The Futurist 16(6): 34-39.

Cour des comptes. 2012. Lessons of the 2010 flooding on the Atlantic coast (Xynthia) and in the Var (Les enseignements des inondations de 2010 sur le littoral atlantique (Xynthia) et dans le Var). Rapport public thématique. Paris: Cour des comptes.

Davenport, T., and L. Prusak. 1998. Working knowledge. Boston: Harvard Business School Press.

DKKV (Deutsches Komitee für Katastrophenvorsorge). 2004. Flood risk reduction in Germany: Lessons learned from the 2002 disaster in the Elbe region. DKKV publication 29e. Bonn: German Committee for Disaster Reduction.

Gaillard, J.C., and J. Mercer. 2013. From knowledge to action: Bridging gaps in disaster risk reduction. Progress in Human Geography 37(1): 93-114.

Gall, M., K. Nguyen, and S.L. Cutter. 2015. Integrated research on disaster risk: Is it really integrated? International Journal of Disaster Risk Reduction 12: 255-267.

Gérin, S. 2011. A method for assessing risks prevention plans as tools linked with insurance of natural disasters: Contribution to having more prevention-oriented public policies (Une démarche évaluative des Plans de Prévention des Risques dans le contexte de l'assurance des catastrophes naturelles: Contribution au changement de l'action publique de prévention). Ph.D dissertation, Université Paris-Diderot - Paris VII, Paris, France.

Glantz, M.H. 2015. Shades of chaos: Lessons learned about lessons learned about forecasting El Niño and its impacts. International Journal of Disaster Risk Science 6(1): 94-103.

Glantz, M.H., and M.-A. Baudoin. 2014. Hydro-meteorological disaster risk reduction: A survey of lessons learned for resilient 
adaptation to a changing climate. Boulder: Consortium for Capacity Building, Institute of Arctic and Alpine Research, University of Colorado.

Groeve, T., K. Poljansek, D. Ehrlich, and C. Corbance. 2014. Current status and best practices for disaster loss data recording in EU member states. Luxembourg: Publications Office of the European Union.

Kasperson, R.E., and M. Berberian (eds.). 2011. Integrating science and policy: Vulnerability and resilience in global environmental change. London: Earthscan.

Kelman, I. 2015. Climate change and the Sendai framework for disaster risk reduction. International Journal of Disaster Risk Science 6(2). doi:10.1007/s13753-015-0046-5.

Kelman, I., J.C. Gaillard, and J. Mercer. 2015. Climate change's role in disaster risk reduction's future: Beyond vulnerability and resilience. International Journal of Disaster Risk Science 6(1): 21-27.

Kolen, B., R. Slomp, W. van Balen, T. Terpstra, M. Bottema, and S. Nieuwenhuis. 2010. Learning from French experiences with storm Xynthia: Damages after a flood. AC Lelystad: Rijkswaterstaat Waterdienst.

López-Peláez, J., and P. Pigeon. 2011. Co-evolution between structural mitigation measures and urbanization in France and Colombia: A comparative analysis of disaster risk management policies based on disaster database. Habitat International 35(4): $573-581$

Milton, N.J. 2014. Findings from international surveys providing a snapshot of the state of KM from a practitioner point of view. Journal of Entrepreneurship, Management and Innovation 10(1): 109-127.

Nonaka, I., and H. Takeuchi. 1995. The knowledge creating company. New York: Oxford University Press.

Nussbaum, R., and P. Pigeon. 2015. A national Public Private Partnership (PPP) platform for risk data sharing to stimulate DRR participative governance in France. A case study series published by the UNISDR Scientific and Technical Advisory Group. http://www.preventionweb.net/files/workspace/7935 rnussbaumpppdrrinfrance.pdf. Accessed 17 Apr 2015.

Pahl-Wostl, C. 2009. A conceptual framework for analysing adaptive capacity and multi-level learning processes in resource governance regimes. Global Environmental Change 19(3): 354-365.

Pahl-Wostl, C., G. Becker, C. Knieper, and J. Sendzimir. 2013. How multilevel societal learning processes facilitate transformative change: A comparative case study analysis on flood management. Ecology and Society 18(4). Article no. 58.

Pigeon, P. 2012a. Contributions of resilience to the geography of risks: The example of La Faute-sur-Mer (Vendée, France) (Apports de la résilience à la géographie des risques: l'exemple de La Faute-sur-Mer (Vendée, France)). VertigO-la revue électronique en sciences de l'environnement 12(1). http://www. vertigo.revues.org/12031. Accessed 12 Apr 2015.

Pigeon, P. 2012b. Paradoxes of urbanization (Paradoxes de l'urbanisation). Paris: L'Harmattan.

Pigeon, P. 2013. Flood risk and watershed management conflicts in France: Upper catchment management of the river Rhone. In Making space for the river: Governance experiences with multifunctional river flood management in the US and in Europe, ed. J.F. Warner, A. van Buuren, and J. Edelenbos, 149-161. London: IWA Publishing.

Polanyi, M. 1967. The tacit dimension. New York: Anchor Books.

Renaud, F.G., K. Sudmeier-Rieux, and M.S. Estrella. 2013. The role of ecosystems in disaster risk reduction. Tokyo: UNU Press.
Renn, O. 2015. Stakeholder and public involvement in risk governance. International Journal of Disaster Risk Science 6(1): 8-20.

Rowley, J. 2007. The wisdom hierarchy: Representations of the DIKW hierarchy. Journal of Information Science 33(2): 163-180.

Select Bipartisan Committee to Investigate the Preparation for and Response to Hurricane Katrina. 2006. A failure of initiative. Final Report of the Select Bipartisan Committee to Investigate the Preparation for and Response to Hurricane Katrina. Washington DC: U.S. Government Printing Office.

Senge, P.M. 1990. The fifth discipline: The art and practice of the learning organization. London: Random House.

Spiekermann, R., S. Kienberger, J. Norton, F. Briones, and J. Weichselgartner. 2015. The disaster-knowledge matrix: Reframing and evaluating the knowledge challenges in disaster risk reduction. International Journal of Disaster Risk Reduction 13: 96-108.

UNISDR (United Nations International Strategy for Disaster Risk Reduction). 2014. HFA Thematic Review: Research Area 2. Priority for Action 3-Core Indicator 1: Relevant information on disasters is available and accessible at all levels, to all stakeholders (through networks, development of information sharing systems etc.). Background paper prepared for the 2015 Global Assessment Report on Disaster Risk Reduction. Geneva: UNISDR.

UNISDR (United Nations International Strategy for Disaster Risk Reduction). 2015a. Making development sustainable: The future of disaster risk management. Geneva: UNISDR.

UNISDR (United Nations International Strategy for Disaster Reduction). 2015b. Sendai framework for disaster risk reduction 2015-2030. http://www.wcdrr.org/preparatory/post2015. Accessed 17 Apr 2015.

Vogel, C., S.C. Moser, R.E. Kasperson, and G.D. Dabelko. 2007. Linking vulnerability, adaptation, and resilience science to practice: Pathways, players, and partnerships. Global Environmental Change 17(3-4): 349-364.

Weichselgartner, J., and E. Brévière. 2011. The 2002 flood disaster in the Elbe region, Germany: A lack of context-sensitive knowledge. In Dynamics of disaster: Lessons on risk, response, and recovery, ed. R.A. Dowty, and B.L. Allen, 141-158. London: Earthscan.

Weichselgartner, J., and R.E. Kasperson. 2010. Barriers in the science-policy-practice interface: Toward a knowledge-actionsystem in global environmental change research. Global Environmental Change 20(2): 266-277.

Weichselgartner, J., and M. Obersteiner. 2002. Knowing sufficient and applying more: Challenges in hazards management. Global Environmental Change Part B: Environmental Hazards 4(2-3): 73-77.

Weichselgartner, J., and B. Truffer. 2015. From co-production of knowledge to transdisciplinary research: Lessons from the quest for producing socially robust knowledge. In Global sustainability, cultural perspectives and challenges for transdisciplinary integrated research, ed. B. Werlen, 89-106. Berlin: Springer.

White, G.F., R.W. Kates, and I. Burton. 2001. Knowing better and losing even more: The use of knowledge in hazard management. Global Environmental Change Part B: Environmental Hazards 3(3-4): 81-92.

Zia, A., and C.H. Wagner. 2015. Mainstreaming early warning systems in development and planning processes: Multilevel implementation of Sendai framework in Indus and Sahel. International Journal of Disaster Risk Science 6(2). doi:10. 1007/s13753-015-0048-3. 